\title{
DIAGNÓSTICO SOCIOAMBIENTAL DO ECOTURISMO NO MUNICÍPIO DE PIRENÓPOLIS - GO
}

Recebido em: 17/06/2012

Aceito em: 21/11/2012

\author{
Humberto Luís de Deus Inácio ${ }^{1}$ \\ Thaís Messias Moraes ${ }^{2}$ \\ Faculdade de Educação Física (UFG) \\ Goiânia - GO - Brasil
}

RESUMO: Esta pesquisa foi desenvolvida por pesquisadores do Grupo de Pesquisa em Esporte, Lazer e Comunicação (GEPELC/Faculdade de Educação Física/UFG). Buscou-se realizar um diagnóstico socioambiental do Ecoturismo no município de Pirenópolis, indicando elementos para o encaminhamento de ações e políticas baseadas nos princípios do desenvolvimento territorial sustentável. Os dados coletados indicam a necessidade de um planejamento mais sistêmico na administração pública, na iniciativa privada, na sociedade civil organizada e entre eles. Apesar de proposições em andamento, o ecoturismo no lugar encontra-se em estágio germinal, com poucas articulações com outras atividades e setores; contudo, a preocupação ambiental demonstrada pelos sujeitos da pesquisa, aponta que é possível desenvolver programas/projetos conjuntos que, ao menos, contenham alguns elementos do Desenvolvimento Territorial Sustentável.

PALAVRAS CHAVE: Turismo. Desenvolvimento Sustentável. Indicadores de desenvolvimento sustentável. Meio Ambiente.

\section{SOCIO-ENVIRONMENTAL DIAGNOSIS OF THE ECOTOURISM IN THE PIRENÓPOLIS CITY}

ABSTRACT: This research was conducted by researchers at the Research Group on Sport, Leisure and Communication (GEPELC/Faculty of Physical Education/UFG). We tried to make a socio-environmental diagnosis of Ecotourism in the city of Pirenópolis, indicating elements for actions and policies based on the principles of sustainable territorial development. The collected data indicate the need for a systemic planning in public administration, the private sector, civil society and in between them. Although proposals in

${ }^{\bar{D}}$ Doutor em Sociologia Política (UFSC, 2007). Professor Adjunto da Faculdade de Educação Física/UFG.

${ }^{2}$ Graduada em Educação Física (UFG, 2011). Professora da Rede de Ensino de Goiás.

- Projeto desenvolvido com financiamentos da Fundação de Apoio à Pesquisa do Estado de Goiás (FAPEG) e Bolsa PIBIC do CNPQ. 
progress, ecotourism is in place in germinal stage, with few linkages with other activities and sectors. However, the environmental concern demonstrated by the research subjects, indicates that it is possible to develop programs/joint projects that, at least, contain some elements of sustainable regional development.

KEYWORDS: Tourism. Sustainable Development. Sustainable Development Indicators Environment.

\section{INTRODUÇÃO}

Este artigo apresenta pesquisa realizada no período de agosto de 2009 a março de 2011, desenvolvida no âmbito do projeto 'Diagnóstico e Propostas para as Práticas de Ecoturismo como vetor de desenvolvimento territorial sustentável no município de Pirenópolis e seu entorno'. Contou com recursos da Fundação de Apoio à Pesquisa do Estado de Goiás (FAPEG) e bolsa de iniciação científica - PIBIC, do CNPQ.

A cidade de Pirenópolis está localizada no interior do Estado de Goiás (Brasil), a aproximadamente $120 \mathrm{~km}$ da capital, Goiânia e a $130 \mathrm{~km}$ da capital federal - Brasília. Situada aos pés da Serra dos Pirineus, a cidade é conhecida pela riqueza natural de sua região, com dezenas de cachoeiras, reservas ambientais, parques, serras, mirantes, monumentos naturais; além da paisagem arquitetônica, uma vez que a cidade foi fundada em 1727 e preserva elementos visuais de uma cidade antiga, sendo Patrimônio Histórico Nacional.

Nesse cenário, em parte por conta de suas condições geográficas, a cidade é considerada pelo Ministério do Turismo como um polo ecoturístico, atraindo turistas em busca da prática de caminhadas, montanhismo, rapel, tirolesa, rafting, bóia-cross, arvorismo, dentre outros. 
Humberto Luís de D. Inácio e Diagnóstico Socioambiental do Ecoturismo no Municipio de Pirenópolis - GO Thaís Messias Moraes

Atualmente, por sua proximidade com Brasília, cidade que será sede de jogos do Mundial de Futebol de 2014, há uma série de ações em curso que visam atrair e receber turistas que se desloquem à região para acompanhar os jogos em Brasília.

Em principio, pesquisar o Turismo, em sua dimensão 'eco', no âmbito da Educação Física pode parecer um tanto quanto deslocado para olhares de outras áreas; entretanto, desde há muito que a Educação Física tem como um de seus eixos de investigação científica e de atuação profissional, o campo do Lazer.

O Lazer é um fenômeno social dos mais relevantes nas sociedades modernas: está no cerne do debate sobre a centralidade do trabalho na vida humana. No Brasil, podese dizer que há registros de estudos neste campo nas áreas da Sociologia, da Antropologia e outras. Contudo, desde a década de 1960 (e mesmo antes disto) há inúmeros estudos, pesquisas e ensaios sobre o tema, desenvolvidos por profissionais da Educação Física, consolidando este campo de conhecimento como um lugar em particular para os estudos do lazer.

Tais estudos estavam mais voltados ao campo da recreação na escola e fora dela. Serviram também, de diversas maneiras, para sustentar programas sociais de governos autoritários e ditatoriais. Contudo, com o passar dos anos, a área se expandiu e a Educação Física sempre esteve à frente desta dinâmica. Fruto de uma perspectiva mais ampliada, pesquisadores do Lazer vão afirmar que tal fenômeno possui inúmeras dimensões, espraiando-se em todas as esferas da vida humana.

Nesta direção, o Turismo enquanto um dos conteúdos do Lazer passou a fazer parte dos objetos de estudo da Educação Física. Com o rigoroso cuidado para não ultrapassar algumas fronteiras acadêmicas, a Educação Física foi, aos poucos, se 
Humberto Luís de D. Inácio e Diagnóstico Socioambiental do Ecoturismo no Municipio de Pirenópolis - GO Thaís Messias Moraes

apropriando mais especificamente das diversas faces do Turismo nas quais as práticas corporais se apresentam como elemento fundante; incluem-se neste escopo as práticas corporais de aventura na natureza (PCANs), elemento transversal de nosso estudo.

As PCANs são também chamadas de Turismo de Aventura, Esportes de Aventura, Esportes Radicais, Atividades de Aventura na Natureza, Esportes Ecológicos e Ecoturismo, entre outras denominações menos conhecidas. Esta quantidade de termos para definir uma atividade específica apenas complica e confunde o entendimento sobre o fenômeno e sobre suas inter-relações sociais, culturais e econômicas. A opção pelo termo PCANs é justificada pela necessidade de um distanciamento de conceitos mais tradicionais como o de esporte ou de atividade física. Conforme Lazzarotti Filho et al. (2010, p.22):

O termo práticas corporais, tal como foi encontrado nos periódicos, foi utilizado nas teses e dissertações com a intenção de problematizar os conceitos atividade física e exercício físico. Argumentam que estes conceitos encontram-se reduzidos à compreensão do movimento pela física clássica, enfatizando aspectos como a locomoção no tempo e no espaço e o gasto de energia. Enfatizam também a preocupação em incorporar aspectos subjetivos, como os sentidos e significados atribuídos pelos sujeitos e pela cultura ao movimento corporal humano.

Além disto, é importante destacar que, neste texto, a) turismo de aventura não é esporte de aventura e, b) as PCANs são um dos diversos conteúdos do Ecoturismo.

Como plano de fundo, além do diagnóstico, pesquisamos também o potencial das PCANs como uma ferramenta para uma sensibilização ambiental, no sentido de interferir positivamente nas relações estabelecidas entre os seres humanos e o meio ambiente, o que é um dos elementos constituintes de um processo de Desenvolvimento Territorial Sustentável (DTS). 
Humberto Luís de D. Inácio e Diagnóstico Socioambiental do Ecoturismo no Municipio de Pirenópolis - GO Thaís Messias Moraes

Esse viés surge a partir da necessidade cada vez maior de respeitar os limites da natureza e compreender como o ser humano tem sido responsável por consequências trágicas ocorrido no meio natural. Numa relação onde não há o reconhecimento de pertencimento à natureza que nos circunda, é comum nos enfrentarmos com problemas como poluição, desmatamento, consumo desenfreado, derretimento das geleiras, perda dos afluentes, extinção de espécies animais, dentre outros.

Partindo dessas questões, a busca por um elemento que consiga mediar essa relação de forma eficiente, nos leva a pensar as PCANs como uma possibilidade de realizar esse elo, uma vez que essas práticas

[...] permitem que as experiências na relação corpo-natureza expressem uma tentativa de reconhecimento do meio ambiente e dos parceiros envolvidos, expressando, ainda, um reconhecimento dos seres humanos como parte desse meio (MARINHO, 2001).

Desenvolver o sentimento de pertencimento ao meio natural estimula o cuidado com a vida, em toda sua amplitude, pois, nesse sentido, cuidar do planeta é cuidar de si mesmo; é aqui que assume importância a ideia do DTS.

Assim, a proposta neste trabalho é diagnosticar as PCANs na região já citada e os vetores sociais, ambientais e econômicos com elas relacionados, dentro do contexto do DTS.

\section{DESENVOLVIMENTO TERRITORIAL SUSTENTÁVEL}

Para apresentar o conceito de DTS se faz necessário, antes, dizer que o mesmo é uma derivação dos princípios de outra proposição - o Ecodesenvolvimento, menos 
Humberto Luís de D. Inácio e Diagnóstico Socioambiental do Ecoturismo no Municipio de Pirenópolis - GO Thaís Messias Moraes

disseminada e, portanto, menos conhecida. ${ }^{3}$

Foi Maurice Strong, em 1973, quem cunhou o termo ecodesenvolvimento, buscando resumir numa palavra uma proposta de desenvolvimento orientado de forma ecológica. O conceito surgiu sob a influência das análises sistêmicas sobre os limites externos do crescimento material, além dos trabalhos preparatórios da Conferência de Estocolmo (VIEIRA, 1995). A ideia principal do novo conceito era sensibilizar os planejadores e gestores para o imbricamento das dinâmicas de degradação ambiental, marginalização socioeconômica e autoritarismo político.

Contudo, tais ideias, circunscritas nas abordagens territoriais do desenvolvimento do final dos anos 1970, foram julgadas como desprovidas da dimensão dos conflitos sociais. Ainda assim, "o vocábulo ecodesenvolvimento não foi adotado pelas organizações da ONU em razão de seu conteúdo demais restritivo no tocante ao crescimento econômico" (CAZELLA, 2002, p.9) - ou seja, recebeu críticas de todas as tendências. Por um lado, os movimentos sociais e a esquerda acadêmica julgaram o ecodesenvolvimento desprovido de projetos socialistas; por outro, foi considerado transgressor demais para os economicistas.

Os críticos do relatório Brundtland ${ }^{4}$ afirmam que o conceito de

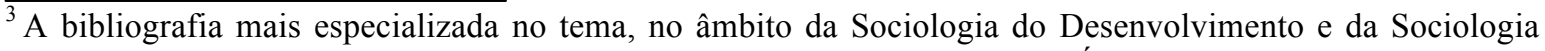
Econômica ignora significativamente o conceito de Ecodesenvolvimento (INÁCIO, 2007).

${ }^{4} \mathrm{O}$ conceito de desenvolvimento sustentável enunciado pelo relatório Brundtland preconiza a satisfação das necessidades da geração atual, levando em conta as necessidades das gerações futuras. Essa definição foi/é suficientemente ampla para acolher tanto os adeptos de uma abordagem menos restritiva do desenvolvimento, como aqueles que defendem uma conservação mais estrita da natureza e outro modelo de desenvolvimento que não os tradicionais; ou seja, naquele momento, atendeu satisfatoriamente a todos os críticos do ecodesenvolvimento.
} 
Humberto Luís de D. Inácio e Diagnóstico Socioambiental do Ecoturismo no Municipio de Pirenópolis - GO Thaís Messias Moraes

‘desenvolvimento sustentável' ${ }^{5}$ surgiu como uma contraposição conservadora ao conceito e aos princípios do ecodesenvolvimento; portanto, com uma face menos revolucionária do que o primeiro.

Os adeptos do ecodesenvolvimento enfatizam as limitações "analíticoreducionistas" no campo das políticas de desenvolvimento sustentável, uma vez que estas apontam tão somente soluções paliativas. Para superar isto, propõem um enfoque alternativo de planejamento e gestão, equidistante tanto da visão economicista quanto da visão estatista, que têm comandado a dinâmica evolutiva das sociedades contemporâneas liberais e socialistas (VIEIRA e WEBER, 1997).

Para os propositores deste enfoque, há a necessidade de focar a categoria de desenvolvimento sob um olhar sistêmico; isto possibilita a integração das várias dimensões associadas às origens da degradação socioambiental, diferentemente dos modelos hegemônicos de desenvolvimento, os quais não favorecem a internalização da problemática socioambiental nas estratégias de planejamento e gestão.

Importa ressaltar que o conceito de ecodesenvolvimento remete a um campo de pesquisas voltadas, de um lado, à análise dos impactos socioambientais de projetos e políticas de desenvolvimento; e, por outro lado, à reflexão sobre estratégias alternativas aos modelos desenvolvimentistas dominantes, o que pode gerar novas tecnologias sociais para o enfrentamento da crise socioambiental.

O enfoque propõe a socialização das informações científicas e sua conexão

\footnotetext{
5 Vargas (1999) realiza uma crítica contumaz à expressão 'desenvolvimento sustentável' e seus desdobramentos; afirma que a crise ambiental é fruto de um determinado padrão de consumo dos países ricos, e que não bastam as propostas de mudanças presentes no conceito de desenvolvimento sustentável para reverter/alterar esta situação; ou seja, Vargas diz que precisamos discutir a própria sustentabilidade do desenvolvimento capitalista. Também Vieira (1995) e Leis (2000) apontam elementos reducionistas no conceito de desenvolvimento sustentável.
} 
Humberto Luís de D. Inácio e Diagnóstico Socioambiental do Ecoturismo no Municipio de Pirenópolis - GO Thaís Messias Moraes

com os conhecimentos ecológicos tradicionais, sustentada num amplo diálogo entre cientistas e comunidades locais. Soma-se a isto a experimentação de dinâmicas de soluções negociadas entre cientistas e comunidades para os problemas locais.

Em sua formulação, o enfoque indica a necessidade de agir sobre as causas estruturais dos problemas e não apenas sobre seus sintomas mais visíveis; para isso, apresenta um conjunto de critérios ou princípios: 1) prioridade ao alcance de finalidades sociais (satisfação de necessidades básicas - materiais e intangíveis - e promoção da equidade); 2) prudência ecológica; 3) autonomia (ou self-reliance) e 4) viabilidade econômica.

O enfoque deve ser visto como uma construção intelectual ainda em processo de elaboração, ou ainda como um conjunto de hipóteses de trabalho extraídas de um novo campo de pesquisa inter e transdisciplinar, que busca enfrentar, numa abordagem preventiva-proativa, os problemas socioambientais, e passíveis de serem submetidas ao crivo da crítica das comunidades científicas (VIEIRA. Relatório Projeto de Pesquisa 'Desenvolvimento territorial: diagnóstico de potencialidades e obstáculos em zonas rurais do estado de Santa Catarina.' Projeto de Pesquisa CapesCofecub 449/04, 2005, 06-10).

No entanto, "apesar da potencialidade embutida no esforço de elaboração do enfoque de ecodesenvolvimento, suas limitações têm sido assinaladas por um volume significativo de autores" (VIEIRA e WEBER, 1997, p.20), e outras experiências e aportes teórico-metodológicos têm sido produzidos.

Nesta direção, pode-se afirmar que o enfoque de ecodesenvolvimento constituiu-se como um precursor no debate que gerou o surgimento do DTS.

Ampliando os conceitos do ecodesenvolvimento, o DTS aponta as noções de 
Humberto Luís de D. Inácio e Diagnóstico Socioambiental do Ecoturismo no Municipio de Pirenópolis - GO Thaís Messias Moraes

'atores e de 'território' como indispensáveis na reflexão sobre o desenvolvimento. Mas não se trata de uma formulação modelo a ser copiada, mas um rol de princípios a serem utilizados de forma criativa e experimental na construção de estratégias territoriais de desenvolvimento justo e equitativo.

Nessas estratégias, as quais buscam responder aos desafios da globalização econômica e cultural, o fenômeno do lazer ganha destaque neste último século.

Sendo uma ampliação (ou derivação) do Ecodesenvolvimento, o DTS apresenta princípios próprios, os quais não se conflitam com os anteriores, e sim os ampliam:

1 - repousa nas iniciativas de atores locais, valorizando os recursos naturais, o patrimônio cultural e arquitetônico, e o conhecimento local disponível na área; 2 - constitui um componente estratégico para a recuperação de áreas econômica, social, política e ambientalmente marginalizadas e degradadas;

3 - estimula relações de complementaridade, num mesmo território, entre as diferentes atividades produtivas ou não implementadas por organizações da sociedade civil, do Estado e da iniciativa privada;

4 - entende/avalia as relações complexas entre as diversas dimensões do processo de desenvolvimento (social, econômica, política, cultural, ambiental);

5 - busca alcançar ao máximo a autonomia da população local em relação às oscilações dos sistemas estadual, nacional e internacional;

6 - não se reduz a uma simples justaposição de iniciativas locais (ainda que bemsucedidas), exigindo a criação e consolidação progressiva de um sistema de planejamento e gestão realmente descentralizado, capaz de assegurar as integrações necessárias à articulação do desenvolvimento local com políticas, estratégias e ações geradas em outros níveis de organização econômica, social e política. Estes princípios devem estar na base de 
Humberto Luís de D. Inácio e Diagnóstico Socioambiental do Ecoturismo no Municipio de Pirenópolis - GO Thaís Messias Moraes

qualquer ação, projeto ou proposta de DTS.

Entretanto, antes de seguirmos, cabe ressaltar que, para Carrière e Cazella (2006), existem três noções ou conceitos que são essenciais para se pensar alguma proposição de desenvolvimento endógeno: o território, a sociocultura e as redes. E ainda, que para as análises desenvolvidas no âmbito da pesquisa aqui apresentada, a noção de rede assume significado fundamental, posto que seja fruto de planejamento, de maneira organizada e sistematizada.

Isto porque as primeiras duas noções (território e sociocultura) são reflexos de um amplo e histórico processo ou dinâmica social, com bases seculares; enquanto que a ‘rede', como já se disse, pode ser construída à luz de uma intenção coletiva.

\section{REDES}

Se o território e a sociocultura são formados por um conjunto de recursos inscritos no modo de vida de uma população, as redes serão constituídas pelos sistemas de relações entre os diversos atores sociais. A intensidade destas relações é que pode potencializar ou reduzir uma dinâmica de desenvolvimento local. Segundo Segundo Marques (2001), uma rede pode ser definida como um conjunto de relações especiais/especializadas com parceiros predefinidos, constituído pelas relações de mercado e buscando atrair elementos externos que permitam reduzir as inseguranças típicas de um processo de inovação.

[...] como um conjunto de ligações seleccionadas e explícitas com parceiros preferenciais no espaço constituído pelas relações de mercado da empresa e tendo como objectivo atrair activos complementares que permitem reduzir as incertezas estática e dinâmica intrínsecas ao processo de inovação. 
Humberto Luís de D. Inácio e Diagnóstico Socioambiental do Ecoturismo no Municipio de Pirenópolis - GO Thaís Messias Moraes

Autor importante neste debate, Putnam (1996) diz que um aspecto fundamental é o processo cooperativo. $\mathrm{O}$ autor debate com outros autores, os quais afirmam que associações fortes e colaborativas podem impedir ações estatais - ou direcioná-las -, uma vez que os interesses de pequenos grupos, mais organizados, podem ser fortes o bastante para tal.

Putnam (1996) aponta o caminho oposto, ou seja, de que uma sociedade forte leva a um Estado também forte, fato este que, em última análise, fortalece a democracia. Neste sentido, parece claro que as condições para a implementação de projetos de DTS requerem o estabelecimento de redes colaborativas.

A noção de rede aponta para outros fatores, tais como concorrência e cooperação entre os atores, ou mais especificamente, entre as empresas. Cabe dizer aqui que a concorrência desejada não é a mesma da ordem capitalista ou liberal. A diferença é que nesta concorrência não há a intenção de 'eliminar' o concorrente, mas apenas de superá-lo, por exemplo, em qualidade e preço. Isto gera uma dinâmica de busca destes atributos por todas as empresas do setor, ampliando e redimensionando a qualidade e a redução dos custos no território. É o que se pode chamar de concorrência colaborativa, que acaba por avançar na direção da cooperação.

Mais concretamente, uma rede envolve formas de cooperação entre as empresas, que podem ser obtidas através de alianças estratégicas, de cooperação técnica, etc., permitindo à empresa ter acesso a tecnologias ou ativos complementares importantes, sem incorrer em custos organizacionais.

Em relação à cooperação, a concorrência colaborativa difere porque não há um processo estabelecido entre as partes de apoio e colaboração. A cooperação pressupõe um 
Humberto Luís de D. Inácio e Diagnóstico Socioambiental do Ecoturismo no Municipio de Pirenópolis - GO Thaís Messias Moraes

acordo entre as partes, entre os atores. Cazella (2002, p.19) destaca que a "circulação das informações constitui, aqui, um elemento-chave desse processo que amalgama a concorrência e a cooperação das empresas".

Um ator destacado na composição destas relações de cooperação são as associações, cooperativas e organizações não governamentais: o desenvolvimento local só tem sentido com a participação direta da sociedade civil organizada. Tal organização pode bem cumprir o papel de intermediar o diálogo entre a população em geral e os governantes.

Ademais, será parceira importante para inovar e agilizar o desenvolvimento local Nas análises deste modelo, contudo, destaca-se que, quando uma dinâmica de desenvolvimento local é institucionalizada, os atores representados pelas associações civis perdem força, especialmente pelo enfrentamento com a história ortodoxa e pragmática da cultura política.

CAZELLA (2002) reforça a necessidade da presença de redes como elementos constituintes do desenvolvimento local:

- é interdependente através de redes, as quais se articulam entre si e com atores externos;

- e sendo rede, é um processo coletivo, o qual se remete a interesses mais amplos que a busca imediata dos lucros econômicos e dos benefícios individuais.

Finalmente, deve-se indicar que a redes podem se constituir de uma combinação eventual de produtos; ou seja, no lugar investigado, não apenas os setores e atividades que compõem o ecoturismo devem conectar-se, mas pode ser tecida uma trama mais ampla, na qual outros setores da economia, bem como da cultura e da educação, podem/devem fazer parte. 
Humberto Luís de D. Inácio e Diagnóstico Socioambiental do Ecoturismo no Municipio de Pirenópolis - GO Thaís Messias Moraes

\section{OBJETIVOS}

\section{Objetivo Geral}

Elaborar um diagnóstico socioambiental das Práticas Corporais de Aventura na Natureza no município de Pirenópolis e seu entorno.

\section{Objetivos Específicos}

- Apropriação dos conceitos e teorias a cerca do Desenvolvimento Territorial Sustentável e das PCANs;

- Compreender as relações sociais, ambientais, econômicas, políticas e culturais, estabelecidas na comunidade alvo da pesquisa;

- Elaboração do diagnóstico socioambiental das PCANs.

\section{METODOLOGIA}

Para a proposta de trabalho apresentada, a fase inicial foi a de formação, que visou:

- A aquisição de conhecimentos mais específicos, não presentes nas disciplinas curriculares do curso de Licenciatura em Educação Física;

- O contato e a familiarização com as ferramentas de diagnósticos socioambientais apresentadas por Inácio (2007);

- O contato e a familiarização com o software ATLAS TI®, que é uma ferramenta para tratamento de dados qualitativos e quantitativos e para a criação de diagramas multiníveis.

No trabalho de campo: 
Humberto Luís de D. Inácio e Diagnóstico Socioambiental do Ecoturismo no Municipio de Pirenópolis - GO Thaís Messias Moraes

- Foram realizadas visitas técnicas, observações e entrevistas;

- Registro em diário de campo das observações, questões, falas de não entrevistados, debates entre os pesquisadores participantes e as demandas derivadas destes registros;

- Registro, por meio de imagens, do campo observado (entenda-se a dinâmica das PCANs acontecendo in loco);

- Identificação, adesão e arquivo de documentos, folhetos, publicidades e todo e qualquer outro material relacionado às PCANs na região estudada;

- Organização da logística (translado, hospedagem e alimentação) para as visitas técnicas, observações e entrevistas.

Os dados coletados estão registrados, etapa que exigiu a transcrição das entrevistas, a digitalização de documentos textuais e a transcrição das observações do diário de campo. Isto feito, foi dado início o tratamento dos dados, identificando, neste processo, a presença ou não das principais categorias de análise elegidas para a pesquisa. O próximo passo constituiu-se da análise dos dados, por meio das categorias de análise definidas anteriormente e à luz do referencial teórico utilizado.

\section{ETAPAS DE EXECUÇÃO}

- Revisão Bibliográfica: Leitura e discussão dos textos relativos às problemáticas do projeto.

- Formação De Pesquisadores: Participação em eventos acadêmicos, cursos e seminários; encontros sistemáticos de estudos intra e intergrupos de pesquisas, especialmente eleitos para a qualificação para pesquisa. 
Humberto Luís de D. Inácio e Diagnóstico Socioambiental do Ecoturismo no Municipio de Pirenópolis - GO Thaís Messias Moraes

- Levantamento de Informações: Realização de consultas bibliográficas e participação das visitas exploratórias.

- Entrevistas: Agendamento e participação nas entrevistas.

- Observações de Campo: Registro de toda atividade investigada por meio de fotografias, diário de campo, filmagens etc.

- Compilação da Base de Dados;

- Produção de Artigos: todo o processo de elaboração, revisão e submissão de artigos aos periódicos e congressos nacionais e internacionais.

- Elaboração do Relatório Final da Pesquisa.

Após as etapas de apreensão de conceitos e conteúdos teóricos necessários para balizar as etapas seguintes, demos inicio às visitas e pesquisas de campo.

Foram realizadas várias visitas à cidade de Pirenópolis, nas quais se realizaram entrevistas com os atuais e ex Secretários Municipais de Turismo e de Meio Ambiente, proprietários de estabelecimentos turísticos, proprietários de terras com cachoeiras, professores do curso de turismo da Universidade Estadual de Goiás (UEG) e moradores da cidade. Foi seguido o roteiro de entrevistas proposto por Inácio (2007).

As entrevistas trataram de temas como: a atuação profissional nos campos de trabalho voltados ao turismo; políticas públicas; trabalhos e parcerias das secretarias municipais; PCANs; regulamentação e fiscalização dos atrativos turísticos; aspectos positivos e negativos do crescimento do turismo; transformações sociais, econômicas, ambientais e políticas da/na cidade e, propostas, programas e ações para o DTS da comunidade, a partir do Ecoturismo. 
Humberto Luís de D. Inácio e Diagnóstico Socioambiental do Ecoturismo no Municipio de Pirenópolis - GO Thaís Messias Moraes

Necessariamente, sempre após as visitas de campo e entrevistas, realizamos um trabalho de transcrição das mesmas e aprofundamento teórico.

\section{ANÁLISE DOS DADOS}

Pirenópolis é uma cidade tombada como conjunto arquitetônico, urbanístico, paisagístico e histórico pelo IPHAN - Instituto do Patrimônio Histórico e Artístico Nacional. Sua arquitetura apresenta um Centro Histórico com casarões e igrejas do século XVIII, e prédios de significativa beleza arquitetônica como o Teatro de Pirenópolis, de 1899, o Cine Teatro Pireneus, de 1919 e a Casa de Câmara e Cadeia construída em 1919 (réplica idêntica do edifício original de 1733).

Mesmo sendo um pequeno município (cerca de 21.000 habitantes), se destaca por ser o que mais possui áreas de preservação ambiental no estado, sendo três delas estatais e cinco privadas (RPPNs) ${ }^{6}$. É cortada por sete rios, entre eles os Rios das Almas e Corumbá, importantes para o Ecoturismo por seus volumes e dimensões.

Por sua vez, o número de cachoeiras é bem maior que o de rios, e as mais importantes para o turismo são: Cachoeira Nossa Senhora do Rosário, Cachoeira Santa Maria, Cachoeiras da Meia Lua, do Abade, das Araras, da Usina Velha, do Lázaro e Cachoeiras do Bonsucesso (esta última é uma sequencia de 7 quedas numa mesma propriedade). Todas se encontram em propriedades privadas; mesmo assim, com mais ou menos estrutura, são abertas ao público, com a cobrança de ingresso. A maior parte delas apresenta apenas a própria queda d'água em si e uma faixa de areia como atrativo; contudo,

\footnotetext{
${ }^{6}$ Reserva Particular do Patrimônio Natural. Estatuto federal que as transforma em área privada de preservação permanente, concedido a particulares proprietários de terras, sob solicitação dos mesmos e após um processo longo e rigoroso.
} 
Humberto Luís de D. Inácio e Diagnóstico Socioambiental do Ecoturismo no Municipio de Pirenópolis - GO Thaís Messias Moraes

em algumas, são oferecidas práticas como rapel e tirolesa. Em outras, há outros produtos agregados, como café colonial, venda de produtos artesanais, etc.

Ainda sobre atrativos turísticos naturais, importa dizer que parte dos turistas que ali chega também se interessa em conhecer e desfrutar da oferta existente nos municípios de Corumbá de Goiás e Cocalzinho de Goiás; ambos limítrofes com Pirenópolis, criando uma interessante conexão entre os mesmos.

À época da pesquisa, havia seis agências de ecoturismo na cidade, oferecendo atividades diversas como: rapel, tirolesa e outras práticas com cordas, arvorismo, caminhadas, bóia-cross, rafting ${ }^{7}$, ciclismo de montanha e cavalgada. Muitas destas atividades eram oferecidas combinadas, em pacotes de dia ou de fim de semana, os quais eram enriquecidos com roteiros arquitetônicos e gastronômicos.

No âmbito da organização social, há algumas associações relacionadas como a de hotéis e restaurantes, a de guias turísticos, a de pousadas, entre outras. Na dimensão da administração municipal, há o Conselho Municipal de Turismo - CONTUR, formado por representantes da administração pública e da sociedade civil.

Fato significativo para o desenvolvimento turístico do território foi a implantação na cidade, pela Universidade do estado de Goiás, de um campi com os cursos de Gastronomia e Tecnologia em Gestão do Turismo. Segundo a coordenação dos cursos [os quais se encontravam com a terceira turma em andamento], nas duas primeiras turmas, a maioria dos alunos era oriunda de outros municípios. Já na terceira turma, a mais recente

\footnotetext{
${ }^{7}$ As atividades nos rios são sazonais: dependem de um bom fluxo de água. Por isso, normalmente, são oferecidas entre os meses de novembro e abril. Entre os meses de maio e outubro, o Centro-oeste brasileiro passa por um período de seca, inviabilizando estas atividades.
} 
Humberto Luís de D. Inácio e Diagnóstico Socioambiental do Ecoturismo no Municipio de Pirenópolis - GO Thaís Messias Moraes

à época, isto de inverteu, demonstrando uma clara repercussão da atividade turística na população local.

Sobre a economia do município, o aspecto mais interessante - e importante, no debate sobre o desenvolvimento do ecoturismo como um vetor de DTS, é que suas principais atividades são a extração mineral (pedras de quartzito para uso na construção civil), e a pecuária extensiva. Estas duas atividades se confrontam com o projeto de constituir aquele território como um polo nacional de ecoturismo. Não é raro, no deslocamento para as cachoeiras, por exemplo, que o turista se depare com amplos pastos substituindo a vegetação nativa, com caminhões transportando pedras, e com as próprias pedreiras, que mais parecem 'feridas' nos verdes morros da cidade. Como conciliar isto?

Conforme já anunciado antes, além destes dados mais gerais, foram coletadas outras informações por meio do roteiro de entrevistas (INÁCIO, 2007). A partir dos dados gerados com este instrumento, organizamos as informações em cinco grupos de variáveis ${ }^{8}$, as quais se explicam a seguir:

1) Político institucional

- Existência de sistemas de planejamento de longo prazo (exemplo: plano diretor, agenda 21);

- $\quad$ Existência de fomento de ações coletivas para a sustentabilidade do desenvolvimento (financiamento de projetos de ONG's ou de movimentos sociais, financiamento de ações diretamente pelo Estado);

- $\quad$ Nível de descentralização política (presença de Conselhos Municipais ou Territoriais, com participação da sociedade);

\footnotetext{
${ }^{8}$ Cf. Flores (2007).
} 
- Acompanhamento e fiscalização (ações diretas da sociedade civil, ação do Ministério Público);

- Articulações da economia local com a dinâmica dos sistemas econômicos nos níveis intermunicipal, regional, estadual, nacional ou internacional;

- Existência de políticas de apoio ao desenvolvimento territorial, adotadas por instituições governamentais;

- $\quad$ A modalidade de ação do Estado Nacional no contexto territorial.

2) Socioeconômico

- Grau de associativismo, cooperativismo e empreendedorismo;

- $\quad$ Existência de cluster, Sistemas produtivos locais (SPL) ou redes;

- $\quad$ Formas de organização das atividades econômicas;

- $\quad$ Nível de emprego;

- $\quad$ Modalidades de geração de emprego e renda;

- Existência de processos de criação e difusão de tecnologias apropriadas;

- Existência de circuitos econômicos locais;

- $\quad$ Nível de integração da agricultura familiar ao mercado;

- Ações de combate à pobreza (com diferenciação entre as de cunho assistencialista e de promoção social).

3) Ecológico 
- $\quad$ Existência de ONGs e partidos políticos que assumam a questão socioambiental como diretriz de mudanças;

- $\quad$ Disponibilidade e modalidade de gestão de recursos naturais;

- $\quad$ Nível de degradação dos recursos naturais;

- Identificação das principais atividades poluidoras;

- $\quad$ Alternativas de gestão de dejetos;

- $\quad$ Existência de diagnósticos e de ações em curso visando à superação das principais fontes de poluição e de degradação ambiental.

4) Cultural

- Existência de mecanismos de integração social (redes associativistas, festas típicas, movimentos sociais);

- Existência de mecanismos de valorização do saber e da cultura local;

- Existência de patrimônio cultural e arquitetônico;

- Modalidade de gestão do patrimônio cultural.

- $\quad$ Sociedade civil

- Existência de associações, sindicatos, instituições religiosas e movimentos sociais em torno de interesses locais;

- Fontes de financiamento das principais organizações da sociedade civil de atuação local;

· Existência de repercussões de ações em outros níveis territoriais. 
Humberto Luís de D. Inácio e Diagnóstico Socioambiental do Ecoturismo no Municipio de Pirenópolis - GO Thaís Messias Moraes

Todas estas variáveis estavam presentes no roteiro de entrevistas, bem como foram buscadas por meio das outras ferramentas de coleta de dados mais acima informadas. Os resultados estão descritos a seguir:

\section{Político-institucionais;}

- Há, entre os funcionários das secretarias municipais, uma parte considerável de pessoas não nascidas em Pirenópolis, nem mesmo na região. cidades. Apesar de não terem se apropriado completamente da realidade local, por estarem a apenas alguns anos na cidade, são considerados os mais capacitados para exercerem suas funções. Segundo alguns entrevistados, estas pessoas 'de fora' estão desempenhando um bom papel no cargo exercido e contribuindo para o desenvolvimento da cidade. Por outra via, políticos pirenopolinos, ou seja, 'locais', tiveram suas ações institucionais reprovadas nas entrevistas;

- As secretarias municipais dizem realizar um trabalho transversal, com envolvimento de todas as secretarias, com sua função específica, nas principais ações do município, principalmente nas festas mais conhecidas da cidade e que atraem um número maior de turistas. Segundo informações, sem organização prévia do conjunto das secretarias, as festas acabam trazendo malefícios e prejuízos para o município e para os turistas;

- Apesar de pequenas parcerias, não há a formação de redes, onde se

pressupõe um planejamento, estruturação e envolvimento de outras instituições, nos trabalhos das secretarias. Há uma pequena parcela de empreendimentos turísticos que se mobilizam em parcerias, o restante acredita na eficiência destas para o desenvolvimento da 
Humberto Luís de D. Inácio e Diagnóstico Socioambiental do Ecoturismo no Municipio de Pirenópolis - GO Thaís Messias Moraes

cidade, mas não tem disponibilidade de tempo, disposição e uma série de fatores que entrevam o desenvolvimento comum;

- A cidade de Pirenópolis foi escolhida, pelo Ministério do Turismo, como um dos 65 destinos indutores do turismo do Brasil, uma vez que está num raio de menos de 150 km de uma cidade sede da Copa do Mundo de Futebol/2014 - Brasília - DF.

\section{Socioeconômicos;}

- A Secretaria Municipal do Turismo vêem desenvolvendo ações, juntamente com o CONTUR, e com a Goiás Turismo ${ }^{9}$, etc., de capacitação profissional, visando à inclusão da comunidade no mercado de trabalho, uma vez que o turismo é o segundo maior gerador de renda da cidade. Boa parte destas ações está envolvida em empreendimentos turísticos, entretanto, sem habilidades e competências necessárias para o desenvolvimento deste, o que faz com que muitas pessoas vindas de fora estejam mais aptas para atender o mercado do que os moradores da cidade;

- Apesar de muitos moradores da comunidade local trabalharem no setor ecoturístico, muitos não tem acesso aos atrativos, cachoeiras, parques, etc, como opções de lazer, nos momentos não associados ao trabalho;

- As secretarias municipais evitam ações que facilitam o acesso de turistas de baixa renda à cidade, como, por exemplo, a instauração de ônibus coletivos que facilitem o trânsito dos turistas dentro e fora da cidade, nos atrativos;

- A UEG, em parceria com a Secretaria Municipal de Educação, realiza projetos pra comunidade estudantil de capacitação profissional, conhecimento dos atrativos

\footnotetext{
${ }^{9}$ Agência Goiana de Turismo.
} 
Humberto Luís de D. Inácio e Diagnóstico Socioambiental do Ecoturismo no Municipio de Pirenópolis - GO Thaís Messias Moraes

turísticos da cidade, implantação da disciplina 'Turismo' na grade do ensino médio, dentre outros;

- A cada ano, desde a criação do curso de Turismo, na Universidade Estadual de Goiás de Pirenópolis, tem aumentado o número de alunos moradores da cidade, reduzindo os alunos que vem de fora e aumentado o nível de profissionalização da comunidade local;

- Apesar da existência de associações (ABRASEL, ABH), elas não são representativas porque a maioria dos empreendedores locais não é participativa, ou seja, não contribui de maneira efetiva nem se apresenta nos encontros e reuniões. Isso acontece, segundo as informações, por falta de tempo, receio de que, a partir da exposição de seu empreendimento, haja necessidade de regulamentar e legalizar seu pequeno negócio, pela alta demanda de tarefas do setor turístico, etc.;

- Com o objetivo de possibilitar o acesso e conhecimento, são concedidos descontos em alguns atrativos turísticos para os moradores da cidade, porém em alguns casos, a intenção motivadora é de que esses moradores sirvam de 'propaganda viva' dos atrativos, principalmente se estes tiverem algum empreendimento no setor turístico.

\section{Ecológicos;}

- O incentivo governamental pra criação de uma RPPN é muito pequeno, o que acaba inviabilizando essa iniciativa pelos proprietários de espaços naturais;

- Os proprietários de fazendas, em Pirenópolis e seu entorno, estão preservando suas propriedades e investindo no turismo rural, que vem crescendo cada vez 
Humberto Luís de D. Inácio e Diagnóstico Socioambiental do Ecoturismo no Municipio de Pirenópolis - GO Thaís Messias Moraes

mais pela valorização de áreas naturais, que rememorem uma volta do ser humano à natureza, ao ambiente natural, uma valorização do bucólico;

- A atividade extrativista das pedreiras, principal geradora de renda do município, tem diminuindo seus impactos ambientais com a utilização de equipamentos mais avançados e iniciativas sustentáveis, a mineração ordenada. Algumas pedreiras já tiveram a iniciativa de transformar em areia os resíduos da pedra, com o uso de britadeira, o que diminui a quantidade de resíduos, além de possibilitar a utilização do mesmo ao ser vendido como areia;

- A Administração Municipal está buscando a regulamentação e fiscalização dos atrativos turísticos naturais, cachoeiras, parques, reservas, etc., no que diz respeito à preservação, conservação e manutenção dos espaços naturais;

- Uma parte dos proprietários dos atrativos ecoturísticos naturais se preocupa com a degradação dos seus espaços e implementa ações para a preservação dos locais, como a limitação da quantidade de pessoas ${ }^{10}$, entrega de sacolas de lixo, limpeza regular, dentre outros, entretanto, a preservação se dá principalmente pela oportunidade de manter lucro sobre o atrativo ali existente;

- Alguns atrativos naturais estão sendo degradados rapidamente: não há controle de carga, manutenção da limpeza local, regulamentação do uso de aparelhagens de som, etc., apontando uma provável busca pelo lucro fácil e momentâneo;

- A busca pelas práticas corporais realizadas na natureza vem deixando de ser o principal fator motivacional do turista que procura a cidade, estando este cada vez mais voltado pras festas e folias nos principais feriados.

\footnotetext{
${ }^{10} \mathrm{De}$ forma amadora, sem estudos de capacidade de carga.
} 
Humberto Luís de D. Inácio e Diagnóstico Socioambiental do Ecoturismo no Municipio de Pirenópolis - GO Thaís Messias Moraes

\section{Culturais;}

- Os atrativos culturais e arquitetônicos são deixados à margem pela Administração Municipal, não há responsáveis pelo atendimento nos museus, não há divulgação e manutenção, os turistas só tem acesso com agendamento, o interesse dos turistas na paisagem urbana está sendo substituído pela paisagem natural;

- A UEG, em parceria com a Secretaria Municipal de Educação, tem um projeto em que os alunos das escolas municipais são levados aos museus da cidade, atrativos, espaços turísticos, etc., visando o conhecimento e a valorização do que a cidade tem para oferecer aos que a procuram;

- Apesar do grande número de turistas que são atraídos pelas festas tradicionais e comemorações culturais da cidade, os moradores locais, durante esses acontecimentos, não visam unicamente o lucro com o turismo, mas sim sustentar a tradição das comemorações, a cultura local e popular. As festas são divididas em três momentos: o momento da preparação, quando a cidade toda se mobiliza para a organização das festividades; os finais de semana da festa, destinados aos turistas que se deslocam para a cidade nessas ocasiões; e os últimos dias da festa, no começo da semana, quando a comunidade vai para aproveitar um pouco desse momento com suas famílias;

- As festas tradicionais pouco a pouco vão sendo modificadas em função das transformações pelas quais passa o município, culturais, econômicas, políticas, religiosas, etc, como também pelas transformações globais, as quais acabam por interferir nas dinâmicas locais; 
Humberto Luís de D. Inácio e Diagnóstico Socioambiental do Ecoturismo no Municipio de Pirenópolis - GO Thaís Messias Moraes

- Vem crescendo cada vez mais o número de turistas que procuram a cidade para as festas do carnaval, semana santa, ano novo, etc., dinâmica esta que está gerando uma cultura de organização e preparação dessas festas pela população local.

\section{Sociedade Civil;}

- São realizadas reuniões de preparação para os grandes eventos que a cidade organiza, nas quais a população local pode participar das mesmas, com direito de interferir nas decisões tomadas pelas secretarias municipais e associações, entretanto, poucos são os moradores que vão a esses encontros;

- Há na sociedade pequenos grupos que se organizam em associações, cooperativas, entidades, partidos e comunidades de moradores, para a organização de regiões, manutenção de interesses e direitos, além de ações sociais e comunitárias, como o trabalho com dependentes químicos, pessoas com diversas necessidades, etc.;

- A comunidade pirenopolina apresenta alguns comportamentos xenofóbicos, preconceito com pessoas vindas de fora, para com alguns moradores da cidade.

\section{CONSIDERAÇÕES FINAIS}

Além das observações apresentadas dentro das cinco variáveis, identificamos algumas questões gerais que consideramos obstáculos para o desenvolvimento territorial sustentável e do turismo na região de Pirenópolis e seu entorno, dentre estas, destacamos:

- A maioria dos empreendimentos turísticos não presta atendimento em línguas estrangeiras, inclusive o Centro de Atendimento do Turista (CAT), onde as 
Humberto Luís de D. Inácio e Diagnóstico Socioambiental do Ecoturismo no Municipio de Pirenópolis - GO Thaís Messias Moraes

atendentes não estão capacitadas para estabelecer comunicação com turistas de outras partes do mundo;

- Durante a semana, a cidade aparenta certa 'inércia', pelo baixo fluxo de turistas; alguns estabelecimentos comerciais não abrem e são encontradas poucas opções de serviços. É considerada uma cidade com 'turismo de fim de semana', conforme o Secretário Municipal de Turismo;

- A maior parte da população da cidade que trabalha com empreendimentos turísticos não possui habilidades e qualificação específicas para tal;

- A cidade ainda apresenta uma política coronelista, onde são efetivados especialmente os interesses dos grandes empreendedores e políticos, sendo abafadas, por exemplo, ações que beneficiam o meio ambiente, mas prejudicam os grandes negócios;

- Os proprietários dos empreendimentos turísticos não se vêem como parceiros no desenvolvimento comum, mas sim como rivais, dificultando o estabelecimento e a criação de redes, embora alguns façam questão de consumir produtos produzidos na região e empregar os nativos da cidade;

- O principal objetivo em se preservar o meio ambiente, presente no discurso dos empreendedores e representantes das secretarias municipais, está associado à preservação para a obtenção de lucros sobre o ecoturismo;

- Uma parte dos políticos responsáveis pela administração da cidade são proprietários de empreendimentos turísticos e não possuem histórico profissional de atuação nas áreas que lhes competem. 
Humberto Luís de D. Inácio e Diagnóstico Socioambiental do Ecoturismo no Municipio de Pirenópolis - GO Thaís Messias Moraes

A cidade de Pirenópolis tem um potencial muito grande de se desenvolver territorial e sustentavelmente, entretanto a principal preocupação ainda é com o desenvolvimento do setor turístico/ecoturístico, embora esse processo acarrete diversos conflitos de ordem econômica, social, ambiental, cultural e política.

Quanto às PCANs, os empreendimentos ecoturísticos da cidade são procurados por pessoas motivadas pela busca da adrenalina, de emoção e de aventura; em segundo plano, se pode observar uma reaproximação com o meio natural.

Isto posto o estudo aponta para a necessidade de uma maior articulação entre o poder público, as associações empresariais e a sociedade civil organizada. Mas não apenas entre estes segmentos como também no interior de cada um deles: o poder público precisa apresentar e desenvolver projetos e ações conjuntas entre as secretarias; as associações empresariais não podem continuar com a perspectiva de que o 'outro' é adversário, mas sim como parceiros; e a sociedade civil deve fortalecer-se para buscar a garantia de seus interesses e direitos.

Esta articulação mais ampliada entre os segmentos e em seus âmbitos específicos pode permitir a formação de redes de cooperação e desenvolvimento justos e equilibrados tal como apontam os princípios do DTS. Além disso, outros setores tangentes às redes também são beneficiados, como, por exemplo, os postos de combustíveis que tem seu faturamento aumentado com o incremento do fluxo turístico, ou os pequenos agricultores que ampliam sua produção para suprir hotéis e restaurantes, entre outros.

Contudo, o que queremos destacar nestas linhas finais é que a constituição de redes não objetiva o enriquecimento de uns em detrimento de outros, mas sim, uma produção e distribuição de riquezas adequada, justa e equilibrada entre as partes que as 
Humberto Luís de D. Inácio e Diagnóstico Socioambiental do Ecoturismo no Municipio de Pirenópolis - GO Thaís Messias Moraes

compõem; o que - em última análise, possibilita a distribuição desta mesma riqueza ao território de maneira em geral. Neste sentido, a reprodução de um dos princípios do DTS é adequada para encerrar este texto:

O DTS não se reduz a uma simples justaposição de iniciativas locais; exige a criação e consolidação progressiva de um sistema de planejamento e gestão descentralizado, capaz de assegurar as integrações necessárias à articulação do desenvolvimento territorial com políticas, estratégias e ações geradas em outros níveis de organização econômica, social e política.

\section{REFERÊNCIAS}

CARRIÈRE, J.P. CAZELLA, A. A. Abordagem introdutória ao conceito de desenvolvimento territorial. ESFORIA. v.4, 2006, p. 23-47.

CAZELLA, A. A. Développement local et agriculture familiale: les enjeux territoriaux dans le département de 1'Aude. Thierval-Grignon. INRA, Mémoires et Thèses, n. 36, 2002, 395 p. Capitulo I traduzido para o Português, 40p.

FLORES, M. X. O desenvolvimento territorial do vale dos Vinhedos/RS: em busca de elementos para o ecodesenvolvimento. 2007. 311f. Tese (Doutorado) Programa de PósGraduação em Sociologia Política. UFSC. 2007.

INÁCIO, H. L. D. O ecoturismo como vetor de Desenvolvimento Territorial Sustentável: um estudo de caso no Alto Vale do Itajaí. 2007. 254f. Tese (Doutorado) Programa de Pós-Graduação em Sociologia Política. UFSC. 2007.

LAZZAROTTI FILHO, A. et al. O termo Práticas Corporais na Literatura Científica Brasileira e sua Repercussão no Campo da Educação Física. Movimento, v. 16, p. 11-29, 2010 .

LEIS, H. A modernidade insustentável. Florianópolis: Editora da UFSC, 2000. MARINHO, A. Lazer, natureza e aventura: compartilhando emoções e compromissos. Revista Brasileira de Ciências do Esporte, Campinas, v. 22, n0. 2, jan., p.143-153, 2001. 
MARQUES, C. S. Inovação e Gestão nas Empresas Industriais de Trás-os-Montes e Alto Douro". In: ENCONTRO NACIONAL DA APDR, 8, 2001. Anais... UTAD: Vila Real, 2001. p. 15-28.

PUTNAN, R. D. Capital social e desempenho institucional. In: Comunidade e democracia: a experiência da Itália moderna. Rio de Janeiro: FGV, 1996, p.173-194.

VARGAS, P. R. O insustentável discurso da sustentabilidade. In BECKER, D.F. (Ed). Desenvolvimento sustentável: necessidade e/ou possibilidade. Santa Cruz do Sul: EDUNISC, 1999. p.207-238.

VIEIRA, P. H. F. WEBER, J. Introdução geral: sociedades, natureza e desenvolvimento viável. In: VIEIRA, P. H. F. WEBER, J. (orgs.) Gestão de recursos naturais renováveis e desenvolvimento. Novos desafios para e pesquisa ambiental. São Paulo: Cortez, 1997. p. $17-49$.

VIEIRA, P.H.F. Relatório Projeto de Pesquisa 'Desenvolvimento territorial: diagnóstico de potencialidades e obstáculos em zonas rurais do estado de Santa Catarina.' Projeto de Pesquisa CapesCofecub 449/04, 2005.

VIEIRA, P. H. F. Meio ambiente, desenvolvimento e planejamento. In: VIOLA, Edson. et al. Meio ambiente, desenvolvimento e cidadania: desafios para as ciências sociais. São Paulo: Cortez, 1995. p. 45-98.

\section{Endereço dos Autores:}

Humberto Luís de Deus Inácio

Rua 01, Chácara 08, casa 01.

Setor de Chácaras Samambaia.

Goiânia - GO - 74691-310

Endereço Eletrônico: betoinacio@gmail.com 